\title{
A espetacularização da fé no espaço sagrado da Igreja Universal do Reino de Deus - Templo Central de Fortaleza
}

\author{
The spectacularization of faith in the sacred space of the Universal \\ Church of the Kingdom of God-Central Temple of Fortaleza
}

\section{Christovam Reis dos Santos Filho ${ }^{A}$}

\author{
${ }^{a}$ Doutorando em Geografia na Universidade Estadual do Ceará (UFC). \\ E-mail: santosfilho20@gmail.com
}

\begin{abstract}
O texto a seguir é uma interpretação acerca da espetacularização da fé pertinente aos espaços de culto neopentecostais. Representada empiricamente pela Igreja Universal do Reino de Deus - Templo Central de Fortaleza (Iurd-TCF), busca-se a compreensão de como ocorre a espetacularização da fé no espaço sagrado do templo. Para isto, intenta-se entender o processo de espetacularização; discernir as características do neopentecostalismo frente ao espetáculo; e apreender a importância do espaço sagrado da Iurd-TCF para propagação do discurso espetacular religioso. Utilizamos a pesquisa bibliográfica e visitas de campo como metodologia e percebemos que este processo é desencadeado por meio da homilética midiática, da "Mcdonaldização" e customização da fé, de geossímbolos irradiados pelo espaço sagrado dos templos e influência dos canais de mídia. Estas características promovem uma religião voltada ao espetáculo, atraente ao gosto do indivíduo. Considera-se, então, que a Iurd-TCF é um espaço espetacular do sagrado. É um grande centro de eventos espiritual, pronto para vender sua principal mercadoria: a fé, baseado no espetáculo como mercadoria, destinada ao consumidor da fé.
\end{abstract}

Palavras-chave: espetáculo, homilética midiática, geossímbolos, espaço espetacular do sagrado.

The following text is an interpretation about the spectacularization of the faith pertinent to neo-Pentecostal spaces of worship. Emphasized empirically by the Universal Church of the Kingdom of God - Central Temple of Fortaleza (UCKG-CTF) the text seeks to understand how the spectacularization of faith occurs in the sacred space of the temple. For such purpose, our article tried to understand the process of spectacularization; to discern the characteristics of neo-Pentecostalism in the face of the spectacle; to grasp the importance of the sacred space of the UCKG-CTF for the propagation of the spectacular religious discourse. We use bibliographical research and field visits as methodology and we realize that this process is triggered by mediatic homiletics, "Mcdonaldization" and customization of faith, geosymbols irradiated by the sacred space of temples and influence of media channels. These characteristics promote a religion oriented to the spectacle, attractive to the taste of the individual. We considered, then, that the IURD-TCF is a spectacular space of the sacred. It is a great spiritual event center, ready to sell its main commodity: faith, based on the spectacle as commodity, intended for the consumer of the faith.

Keywords: spectacle, media homiletics, geosymbols, spectacular space of the sacred. 


\section{INTRODUÇÃO}

O presente ensaio é a tentativa de promover a discussão acerca dos espaços sagrados neopentecostais. Percebemos na sociedade contemporânea a inserção da religião em vários canais de rádio e televisão, além de shows, eventos em espaços públicos e, sobretudo, o crescente número de templos neopentecostais dedicados à prática da fé. Essa nova demanda social promoveu uma maneira peculiar de viver e expressar a religião. O espetáculo está cada vez mais presente nestes locais.

O discurso religioso direciona seus esforços em busca de fiéis consumidores dos bens simbólicos, apresentando uma "forma de ver" a fé. Isto se reflete nos espaços sagrados adaptados cada vez mais às regras de mercado, cujas trocas são simbólicas e materiais, inclusive com sistema de crédito.

Buscamos aproximar este mundo espetacular ao contexto crescente do neopentecostalismo. A partir das ideias de Guy Debord (2003) procuramos elencar elementos que nos auxiliem na compreensão da formação de espaços sagrados neste segmento religioso no Brasil.

Assim, nosso questionamento central investiga como ocorre a espetacularização da fé nas igrejas neopentecostais. Para fins de pesquisa e a grandiosidade do campo religioso brasileiro, delimitamos nosso estudo a apenas um templo neopentecostal. O recorte empírico é a Igreja Universal do Reino de Deus - Templo Central de Fortaleza (Iurd-TCF), localizada no centro da capital cearense. A escolha por este templo se justifica por ter sido objeto de pesquisa para nível de mestrado e por proximidade geográfica do pesquisador, além do templo ser de aparência opulente na paisagem cotidiana de quem frequenta a área central de Fortaleza.

Nossa metodologia consiste basicamente em pesquisa bibliográfica e observações de campo. Os referenciais teóricos se referem a estudos interpretativos sobre o espetáculo, tendo como referência inicial o francês Guy Debord, em sua obra $A$ sociedade do espetáculo, para compreensão do conceito. No que se refere aos estudos religiosos, partimos de Mariano (2012) para delimitar e caracterizar nosso estudo empírico. E na abordagem geográfica conciliamos nosso entendimento aos estudiosos da religião na geografia como Rosendahl (2008) e Gil Filho (2008), além da compreensão do conceito de geossímbolo (BONNEMAISON, 2002), que elucida a compreensão de como certos espaços são assimilados como diferentes e importantes para determinado grupo.

As observações de campo foram extraídas enquanto fazíamos nossa dissertação. Constituiu-se de visitas in loco, anotações de campo e conversas com frequentadores do templo e, mediante concessões, entrevistas semiestruturadas para responder a questionamentos referentes à compreensão do espaço sagrado.

Elencamos um objetivo geral para este ensaio, mediante três objetivos específicos. No geral, busca-se compreender como ocorre a espetacularização da fé no espaço sagrado da Iurd-TCF. Especificamente, intenta-se entender o processo de espetacularização; discernir as características do neopentecostalismo frente ao espetáculo; $\mathrm{e}$ apreender a importância do espaço sagrado da Iurd-TCF para propagação do discurso espetacular religioso.

\section{O ESPETÁCULO NA SOCIEDADE CONTEMPORÂNEA}

A palavra "espetáculo" é uma daquelas palavras que somente em ser pronunciadas nos lança a uma quantidade razoável de definições e ideias. Formalmente, o espetáculo é definido primeiramente como "tudo o que atrai a vista ou prende a atenção" . Neste caso, tudo que desperta o interesse de uma pessoa pode ser um espetáculo, inclusive as relações sociais, pois a partir do momento que nos interessamos por estar com alguém ou por nos comunicarmos com outras pessoas, mesmo que nessa comunicação haja apenas um falante. Logo, as relações religiosas, as visitas aos templos ou simplesmente assistir a um programa televiso religioso, por definição, já faz parte do espetáculo, uma vez que desperta o interesse.

Deste modo, o espetáculo é uma forma de apresentação e representação, isto é, parte das relações sociais. Isto nos remete a distinguir o conceito de espetáculo do senso comum, aquele das peças teatrais ou um filme cinematográfico, com sua cientificidade. Tomando por base que "o espetáculo não é um conjunto de imagens, mas uma relação social entre pessoas, mediatizada por imagens" (DEBORD, 2003, p. 14), percebemos que as interações entre as pessoas ocorrem também por um conjunto de imagens que são simbolizadas através da linguagem. Essas interações criam um repertório simbólico, ao ponto de a realidade assumir um tipo de encenação decorrente pelas trocas econômicas que as mercadorias geram.

Continuando o pensamento do autor supracitado, também podemos considerar o espetáculo como algo

1 Disponível em: encurtador.com.br/elwKV. Acesso em: 10 jul. 2017. 
inapreensível, que obscurece a realidade. Neste caso, as relações que envolvem o imaginário ou o transcendental são privilegiadas pela linguagem do espetáculo, uma vez que

Onde o mundo real se converte em simples imagens, estas simples imagens tornam-se seres reais e motivações eficientes típicas de um comportamento hipnótico. O espetáculo, como tendência para fazer ver por diferentes mediações especializadas o mundo que já não é diretamente apreensível, encontra normalmente na visão o sentido humano privilegiado que noutras épocas foi o tato; a visão, o sentido mais abstrato, e o mais mistificável, corresponde à abstração generalizada da sociedade atual. Mas o espetáculo não é identificável ao simples olhar, mesmo combinado com o ouvido. Ele é o que escapa à atividade dos homens, à reconsideração e à correção da sua obra. É o contrário do diálogo. Em toda parte onde há representação independente, o espetáculo de reconstitui-se. (DEBORD, 2003, p. 19, grifos do autor)

Assim, as relações que envolvem a religião também são espetaculares. A realidade deixa de ser apreensível em sua totalidade para ceder aos estímulos abstratos do que se vê, tornando-se real para quem a vê.

Entendendo que a sociedade contemporânea se molda por meio de espetáculos, notamos que as mídias visuais ganharam força nesta comunicação, além de funcionarem privilegiando a visão. Observamos como as emissoras de televisão e rádio perpetuam ideias, conhecimentos dos mais variados, histórias de pessoas e, sobretudo, produtos para serem consumidos. As empresas passaram a adotar o espetáculo midiático como ferramenta indispensável para venda de suas mercadorias, buscando uma aproximação com os mais variados públicos.

Ou podemos nos usar da seguinte afirmativa:

Com a empresarialização das mídias, como estratégia de subsistência comercial, as emissoras passam a uma relação bem mais estreita com novos atores sociais, por exemplo, a Igreja; que, por sua vez, percebe uma possibilidade real de se posicionar nesse mercado promissor, especialmente considerando seus déficits causados pelo trânsito religioso. (FREITAS JÚNIOR, 2009, p. 198-199)

Deste modo, a espetacularização passa a ser uma importante ferramenta para sucesso das empresas. Podemos dizer que a "espetacularização e a alta visibilidade, construídas no ambiente midiático, são estratégicas para que discursos e ações (políticas) alcancem êxito hoje" (HERSCHMANN, 2005, p. 153). Isto percorre não somente para empresas comerciais de produtos básicos ou de serviços, mas passa a ser generalizada numa sociedade em que a conectividade cresce a cada dia.

A religião também se utiliza do espetáculo para promoção de suas ideias filosóficas ou venda de produtos de seu setor. Neste caso, o consumo também perpassa pela religiosidade das pessoas, que apelam às mais variadas maneiras de suprir suas carências transcendentais, influenciadas pelo discurso dos líderes das igrejas ou grupos religiosos.

O espetáculo é uma ferramenta essencial para promoção da fé. Esta entendida como "convicção da existência de algum fato ou da veracidade de alguma asserção" (MICHAELIS, 2015), também se espetaculariza mediante a atração dos fiéis para o consumo dos bens simbólicos. Este consumo confere poder ao fiel escolher aquilo que quer consumir, configurando uma individualização da prática religiosa, mesmo que em espaços coletivos, pois

Ao apoiar-se no capitalismo, que autoriza e induz o ser humano para consumir e ser consumido pelo objeto do seu desejo, o individualismo religioso cada vez mais se acirra e motiva as pessoas a serem, ao mesmo tempo, obcecadas pelos valores materiais e por aquilo que estes podem lhes proporcionar. (GABATZ, 2012, p. 1764)

Neste contexto, podemos dizer que a fé é vendida nos moldes de mercado. E como algo que se vende, precisa despertar o desejo dos potenciais consumidores. Por isso, o discurso religioso é fundamental para o êxito.

Por meio da leitura de Ramos (2006), podemos sinteticamente elencar aquilo que ele considera como fatores da idade mídia no mundo religioso:

Tabela 1. Características da prática homilética contemporânea.

1. A mídia se revestiu da aura religiosa.

2. Os sentidos triunfaram sobre a mente, a emoção sobre a razão.

3. Quando a religião se serve desse canal de comunicação, sua mensagem, necessariamente, deve se amoldar às exigências mercadológicas próprias do meio. 
Tabela 1. Continuação.

4. A homilética desloca-se do campo do verbal-oral para o imagético-visual.

5. Os telepregadores tendem a se ocupar menos com a verdade do que com o que parece ser a verdade.

6. Parte da emoção para influenciar a razão.

7. Não importam as causas e razões, mas as afirmações e as repetições.

8. A prédica nos meios de comunicação de massa exige alto grau de redundância e simplificação.

9. Os temas preferidos do universo espetacular são o jogo, a violência e o sexo.

10. As desgraças humanas se converteram numa das principais moedas de troca no mercado televisivo.

Fonte: RAMOS (2006), p. 124-126. (Adaptação a partir do texto do autor).

Estes fatores mostram que a espetacularização da fé é um modo de propagação religiosa que envolve características da sociedade contemporânea. Esta ideia nos volta para Debord, uma vez que o mundo da mercadoria é realizado pelas relações sociais, inclusive pela forma como os pastores se comportam no altar, que é um palco do sagrado e fonte irradiadora daquilo que os fiéis desejam superar. Os pastores adotam uma postura espetacular, bem como o próprio local de culto. Destacaremos neste texto, a partir da seção seguinte, as características concernentes à espetacularização da fé.

\section{RELIGIÃO E FÉ NA SOCIEDADE DO ESPE- TÁCULO: O CASO NEOPENTECOSTAL}

Como já dito, a religião faz parte destas relações e, por sua vez, estão neste processo de espetacularização. Percebemos isto por meio da difusão da religião no Brasil, sobretudo nas igrejas pentecostais e neopentecostais. Delimitaremos nosso texto, sobretudo, ao segmento neopentecostal, por meio da Iurd-TCF, pois é responsável pelas maiores taxas de crescimento em número de adeptos no país. Usamos a classificação histórico-institucional de Freston (1993) e a caracterização de Mariano para distinguir nosso recorte empírico, dentre as igrejas brasileiras.

Sobre a classificação de nosso empírico, temos a seguinte disposição:

A primeira onda é a década de (1910), com a chegada da Congregação Cristã (1910) e da Assembleia de Deus (1911) [...] A segunda onda pentecostal é dos anos 50 e início dos anos 60, [...] surgem: a Quadrangular (1951), Brasil Para Cristo (1955) e Deus é Amor (1962) [...] A terceira onda começa no final dos anos 70 e ganha força nos anos 80 . Suas principais representantes são a Igreja Universal do
Reino de Deus (1977) e a Igreja Internacional da Graça de Deus (1980). (FRESTON, 1993, p. 66)

Por este arranjo, fica evidente que a Iurd-TCF é considerada como de terceira onda. Tanto por ser uma instituição relativamente jovem, como também por aderir doutrinas e rituais diferentes dos grupos anteriores. Ela possui características peculiares que inclusive influenciaram outras assembleias na adesão das ideias neopentecostais.

Mariano argumenta da seguinte forma:

Sobre as características do neopentecostalismo, destaco três aspectos fundamentais: 1) exarcebação da guerra espiritual contra o Diabo e seu séquito de anjos decaídos; 2) pregação enfática da Teologia da Prosperidade; 3) liberalização dos estereotipados usos e costumes de santidade.

(MARIANO, 2012, p. 36)

Estes atributos formaram um perfil de fiel aos moldes do individualismo e consumismo ao defender a Teologia da Prosperidade, pelo menos no caso brasileiro. Consumir, neste caso, é uma dádiva dada ao fiel obediente. A Iurd, uma das pioneiras do neopentecostalismo, buscou a evangelização midiática radiofônica e televisiva para arrebanhar novos fiéis.

Parte do sucesso se deve à forma de difusão de evangelização promovida pela instituição, que usa do espetáculo para compartilhar as crenças. O espetáculo serve para propagação de bens simbólicos, pois a classe que domina esses bens promove maneiras de chamar a atenção das pessoas a aderirem sua doutrina ou filosofia religiosa. Para isso

O processo conducente à constituição de instâncias especificamente organizadas com vistas à produção, à reprodução e à difusão dos bens religiosos, bem como a evolução 
(relativamente autônoma no respeito às condições econômicas) do sistema destas instâncias no sentido de uma estrutura mais diferenciada e mais complexa, ou seja, em relação a um campo religioso relativamente autônomo se fazem acompanhar por um processo de sistematização e de moralização de práticas e de representações religiosas que vai do mito como (quase) sistema objetivamente sistemático à ideologia religiosa como (quase) sistema expressamente sistematizado e, paralelamente, do tabu, e da contaminação mágica do pecado, ou do mana, do 'numinoso' do Deus primitivo, arbitrário e imprevisível, ao Deus justo e bom, guardião protetor da ordem da natureza e da sociedade. (BERGER, 2013, p. 37)

Aliado a isso, há o imediatismo das relações sociais, assinaladas por Bauman (2012) como líquidas. Ele diz que "de modo geral, as relações humanas não são mais espaços de certeza, tranquilidade e conforto espiritual. Em vez disso, transformaram-se numa fonte prolífica de ansiedade" (BAUMAN, 2012, p. 67). Como as relações humanas são (des)confiantes em tempos líquido-modernos, as pessoas se direcionam a um consumo de bens para revigoramento sentimental pessoal dos adeptos, estes mais fáceis serem influenciados por grupos religiosos que pregam o imediatismo para solucionar suas incertezas.

Portanto, este processo de espetacularização propagado pelas igrejas neopentecostais se caracteriza basicamente por três aspectos elencados aqui, baseados em leituras sobre o assunto:

\section{Fé como meio comercial}

Se a religião é um bem simbólico, como defende Bourdieu (2007), a fé passa a ser comercializada dentro dos moldes da religião e esta passa a conformar-se ao mercado. Então aquilo em que as pessoas devem acreditar passa a ser moeda de troca, pois as instituições religiosas vendem produtos ou pedem arrecadações em permuta de um discurso promovido por meio do espetáculo, uma vez que o fiel tem a opção de comprar ou não o anúncio religioso. De outro modo, "a adesão à religião passa a ser voluntária, dependendo da escolha e da preferência do indivíduo, e, por isso, é uma religião limitada à vida privada, sem com isso desempenhar a tarefa anteriormente clássica" (SANTANA, 2005, p. 62). Isto colabora para o processo de secularização defendida por Berger (2013, p. 119) como "o processo pelo qual setores da sociedade e da cultura são subtraídos à dominação das instituições e símbolos religiosos", que limita o domínio das instituições, apelando ao mercado como meio de atrair seguidores.
Assim, a crença, os ritos, as relíquias e demais objetos de culto, o espaço sagrado, entre outras formas de praticar a fé são secularizados para atração de novos fiéis. Podemos concordar que "o mundo é secularizado, assim como suas preferências, o que faz com que os produtos religiosos se adequem às consciências secularizadas" (SANTANA, 2005, p. 63). As pessoas ainda se encantam pelo sagrado, mas desde que atenda às suas necessidades imediatas, não medindo esforços para fazerem parte do espetáculo destinado para seus desejos.

\section{O pastor espetacular}

As instituições religiosas tiveram que se enquadrar aos moldes presentes na contemporaneidade. Como afirma Moreira (2011, p. 6): "Ao se estabelecer o estreitamento da relação entre religião e consumo, com a consequente mercantilização do sagrado, as igrejas, em especial as neopentecostais, passaram a se pautar pelas estratégias de comunicação e marketing". Deste modo, os bispos e pastores tiveram que atribuir novas posturas ao seu discurso e assim despertar os desejos e necessidades dos fiéis.

Para que esses desejos possam ser supridos por meio da fé, o espetáculo precisa contar com seus atores, e estes precisam estar atualizados ao gosto dos fiéis, sem perder de vista sua ideologia e doutrina. O papel do representante pastoral deixa de ser repetitivo e baseado na teologia, para dar lugar ao ilustre pregador que tem várias habilidades de chamar a atenção dos visitantes ou espectadores. A mídia contemporânea auxiliou muito neste ínterim, pois

Não há como negar a influência da mídia sobre o indiví-
duo moderno, uma vez que se vive em meio aos padrões e
modelos estabelecidos midiaticamente. [Assim] se alastra a
figura do apresentador, animador e espetacular pastor a fim
de responder aos anseios dos fiéis que estão em busca do
espetáculo e desejam viver o show da vida em suas próprias
experiências. (FREITAS, 2014, p. 234)

No caso neopentecostal representado pela Iurd-TCF, os pastores são treinados para prestarem elevada atenção aos fiéis, quando atuam como auxiliares e a serem os mais criativos possíveis quando atuam diretamente no espetáculo, no altar. Eles precisam saber de tudo um pouco. Desde assuntos religiosos, como os "sintomas" do pecado e suas "curas", bem como de assuntos sociais, econômicos, políticos e até mesmo psicológicos. Mesmo sem a formação adequada comprovada, eles perpassam como guias para todos estes assuntos por meio da persuasão de seu desempenho. 


\section{A "Mcdonaldização" da fé}

Assim como uma empresa que quer vender suas mercadorias, as instituições religiosas entram em concorrência no campo religioso disputando a atenção dos possíveis fiéis e lutando para permanecer os que já são fiéis declarados. Promovem um campo religioso. "A ideia de campo religioso se insere em sociedades em que existe uma condição de disputa competitiva entre as diversas denominações, em busca do maior número dos fiéis possíveis" (PAEGLE, 2008, p. 87). O espetáculo se acirra e se inova a cada dia atrelando novos rituais e ritualizando com novos objetos e ideias para vencerem a disputa.

O autor acima compara a religião evangélica que compõe, segundo ele, os ramos anglicanos, luteranos, reformados, paralelos à Reforma Protestante e pentecostais - a uma rede de fast foods. Todos os ramos disputam com o catolicismo e com religiões afro-brasileiras, além de outras religiões por novos praticantes, o que se assemelha ao conjunto de restaurantes que se inovam a cada dia para venderem as mesmas mercadorias.

Pactuamos com ele quando diz que

Temos uma ideia da "Mcdonaldização" da fé, na medida em que a lógica de mercado é imposta nesta sociedade neoliberal. Forma-se um drive thru religioso, onde o fiel serve-se de acordo com as suas preferências, marcado num contexto histórico do final da década de 1980 e início dos anos 1990, pela redemocratização do país, a queda do Muro de Berlim e o fim da Guerra Fria e da própria União Soviética. Dentro desse panorama histórico, a vitória da sociedade de mercado também influencia o contexto religioso, tornando o país, do ponto de vista religioso, mais plural e com uma concorrência religiosa mais acirrada. (PAEGLE, 2008, p. 91)

Em sintonia com a ideia acima também está Karnal (2015, p. 4), ao dizer que "o que existe hoje é uma customização de Deus, cada um cria um Deus à sua imagem e semelhança. Eu faço o meu Deus, eu faço as minhas regras". Ou seja, há uma adaptação da religião ao fiel, e não o oposto, como nas sociedades primitivas.

Portanto, nos casos acima inferimos que há hoje um coquetel religioso, uma mcdonaldização da fé (PAEGLE, 2008), em que a experiência religiosa tem se modificado e se tornado um espetáculo. Os espaços nos quais o espetáculo ocorre também se adaptam ao modelo espetacularizado. Cabe, então, analisar a influência destes espaços que permanecem ativos mesmo em meio à homilética midiática (RAMOS, 2006) nos modelos de culto.

\section{A espacialização dos espaços midiáticos do sagrado}

É importante frisar que nosso estudo possui uma vertente geográfica, na qual os conceitos de geograficidade e espaço sagrado são relevantes para entender o fenômeno religioso. Por isto, vamos brevemente elucidar tais conceitos e associá-los à temática proposta.

Por geograficidade, entendemos como relacionado ao que é espacial. As experiências pessoais ocorrem no espaço e são por ele afetados ou influenciados. "Cabe observar que a geograficidade, enquanto essência, define uma relação - a relação do ser-no-mundo" (HOLZER, 2015, p. 151), isto é, a relação que o homem tem com a terra que habita. Na religião, o espaço condiciona e é condicionado pelos rituais religiosos, bem como no discurso de quem propaga sua doutrina religiosa.

Tratando-se de espaços destinados aos atos religiosos, chamamos a atenção ao espaço sagrado. Partimos do entendimento de espaço sagrado como "um campo de forças e de valores que eleva o homem a si mesmo, transpondo-o para um meio distinto daquele no qual transcorre seu cotidiano" (ROSENDAHL, 2008, p. 7). Este "é produto da consciência religiosa concreta, e, nesse caso, não é possível a separação entre posição e conteúdo, pois o último parte de uma consciência do vivido plenamente sensível" (GIL FILHO, 2008, p. 71). Os templos são, no caso neopentecostal, como a IurdTCF, exemplos de lugares onde se irradia o sagrado.

Contudo, o espaço sagrado não se limita somente ao que é concretizado. Concordamos que "o espaço sagrado poderia ser destacadamente uma conjunção de espacialidades da experiência religiosa; ao invés de unicamente ser uma base fixa locacional" (PEREIRA, 2014, p. 114). Por isto, advogamos que a mídia ajuda a promover estes espaços, pois a Iurd-TCF, assim como outras neopentecostais, "emprega frequentemente telefone, imprensa, rádio e televisão, com maior grau de profissionalização, usando-o na divulgação de seus princípios, na atração de novos fiéis, na aculturação de sua 'membresia"' (CAMPOS, 1997, p. 245). Logo, nestes espaços o espetáculo é propagado midiaticamente, além de a própria mídia ser sacralizada. Verificamos isto em nosso empírico quando ocorre o momento da "oração do copo com água", em que o bispo, via canal de televisão, convida os telespectadores a colocarem um copo cheio d'água em cima ou próximo ao televisor e ouvirem a oração que o próprio bispo faz.

Entretanto, nos templos, o que atrai a atenção dos fiéis é a seletividade dos ritos durante um culto. Conforme Paegle (2008, p. 95) “o happening, ou seja, o acontecimento, 
que, neste caso, se refere à experiência religiosa, passa a ser mais valorizado do que a doutrina para o crescimento em número de fiéis", daí serem lotados os templos, pois o membro vai, mas participa ativamente apenas do que lhe agrada, cultivando uma fé personalizada, conforme o tipo de necessidade que pretende suprir.

Nos templos também são criados objetos ou detalhes na construção que são identificados pelo fiel como algo próximo aos seus interesses. É o caso do geossímbolo que "pode ser definido como um lugar, um itinerário, uma extensão que, por razões religiosas, políticas ou culturais, aos olhos de certas pessoas e grupos étnicos assume uma dimensão simbólica que os fortalece em sua identidade" (BONNEMAISON, 2002, p. 119). No caso em questão, alguns são identificados pelos próprios fiéis, como o altar, a fachada do templo, a célebre frase "Jesus Cristo é o Senhor", presente em letras douradas acima do altar, entre outros detalhes que reforçam no fiel a sua crença.

Analiticamente, observamos que na Iurd-TCF as reuniões são promovidas através de um calendário semanal, em que cada dia da semana corresponde a um tipo de interesse aos fiéis. Dentro de cada programação, o fiel percebe que o sagrado se apresenta naquele local por ser fonte de sanar sua dificuldade pessoal. Ao adentrar no templo, ele percebe que as atenções se voltam para si, por meio de uma recepção aberta e atenciosa por parte dos obreiros e pastores. Quando o culto começa, o pastor se coloca como um portador da mensagem que Deus dirige a cada um. Isto faz com que o indivíduo participe individualmente, mesmo junto à comunidade, pois o desejo pessoal será atendido mediante a fé. Assim o fiel escolhe a que referências ouvir e a que campanhas pretende praticar, pois estas são elencadas a partir das dificuldades cotidianas de cada indivíduo. O espetáculo, neste caso, é promovido pelos pastores para o que os fiéis querem ver, aquilo que se deve apresentar, como a etimologia da palavra sugere.

Portanto, pelo entendimento que dissertamos sobre o espetáculo, a Iurd-TCF faz do templo, assim como das mídias e dos pastores, um conjunto espetacular, no qual a fé também se torna um espetáculo, para ser assimilada, desejada e trocada pelos fiéis. A atenção se volta para o fiel, e não para a doutrina. O poder que a instituição detém é propagado espacialmente pela monumentalidade de seu prédio como pelo simbolismo transmitido de que é "a concretização da 'obra de Deus" (GOMES, 2011, p. 135). Os templos passam a ser centros de conveniência simbólicos, por meio de geossímbolos que identificam o fiel e o faz perceber que suas aflições podem ser remediadas.

\section{CONSIDERAÇÕES FINAIS}

Neste ensaio defendemos que nas igrejas neopentecostais, representadas empiricamente pela IURD-TCF, ocorre uma espetacularização da fé por meio da homilética midiática, da "Mcdonaldização" da fé, da customização da fé, de geossímbolos irradiados pelo espaço sagrado dos templos e influência dos canais de mídia. Isto promove a ideologia religiosa destas instituições e atrai mais pessoas para os momentos presenciais da igreja. Ou seja, estas características promovem uma religião voltada ao espetáculo, atraente ao gosto do indivíduo.

Ao entendemos que o espetáculo é resultante de um processo alienante, logo assumimos que os dirigentes religiosos buscam atrair mais adeptos por meio de um discurso que preencha seus interesses. Todavia, ele precisa despertar nos possíveis clientes o desejo de fazerem parte do grupo. As mídias auxiliam na propagação do discurso religioso por meio de sua abrangência massiva e por sua adaptabilidade aos moldes do mercado.

Assim, a fé passa a atender ao consumo. Quem decide como vivenciar a fé é o próprio fiel. Desse modo, as igrejas precisam realçar o discurso para o indivíduo. As promessas e auxílios devem convencer o fiel a responder com a sua participação. O resultado é que o espetáculo deixa de ser somente um instrumento para ser a essência vivencial da fé.

Portanto, a Iurd-TCF é um espaço espetacular do sagrado. É um grande centro de eventos espiritual, pronto para vender sua principal mercadoria: a fé. Em um templo neopentecostal, como a Iurd-TCF, há um "cardápio espiritual" à disposição do fiel e/ou visitante. Um ambiente favorável, com símbolos facilmente identificados e total liberdade de escolha de qual programação de fé participar. O pastor se porta como um mediador entre o transcendente e o evidente, mas com atributos conquistadores da credibilidade da assembleia, pois seu discurso é direcionado aos desejos individualizados das pessoas como solução para problemas financeiros, profissionais, conjugais/familiares ou espirituais.

\section{REFERÊNCIAS}

BAUMAN, Z. Medo líquido. Zahar: Rio de Janeiro, 2012.

BERGER, P. L. O dossel sagrado: elementos para uma teoria sociológica da religião. São Paulo: Paulus, 2013. 
BONNEMAISON, J. Viagem em torno do território. In: CORREAA, R. L.; ROSENDAHL, Z. (org.). Geografia cultural: um século. Rio de Janeiro: Eduerj, 2002. p. 83-132.

BOURDIEU, P. A economia das trocas simbólicas. São Paulo: Perspectiva, 2007.

CAMPOS, L. S. Teatro, templo e mercado: organização e marketing de um empreendimento neopentecostal. Petrópolis, RJ: Vozes, 1997.

DEBORD, G. A sociedade do espetáculo. São Paulo: Projeto Periferia, 2003.

FREITAS, H. G. de. Pastor espetacular: a imagem do pastor na sociedade midiática. Discernindo, São Paulo, v. 2, n. 2, p. 225-236, 2014.

FREITAS JÚNIOR, A. L. de. Pistas teológico-práticas sobre a relação entre mídia televisiva e religião a partir do caso Marcelo Rossi. Revista Caminhando, São Paulo, v. 14, n. 2, p. 195-207, 2009.

FRESTON, P. Protestantes e política no Brasil: da constituinte ao impeachment. 1993. Tese (Doutorado em Sociologia) - Instituto de Filosofia e Ciências Humanas, Universidade Estadual de Campinas, Campinas, 1993.

GABATZ, C. A questão do dinheiro na religiosidade neopentecostal. In: CONGRESSO INTERNACIONAL DA FACULDADES EST, 1., 2012, São Leopoldo. Anais [...]. São Leopoldo: EST, 2012. p. 1757-1771.

GIL FILHO, S. F. Espaço sagrado: estudos em geografia da religião. Curitiba: Ibpex, 2008.

GOMES, E. de C. A era das catedrais: a autenticidade em exibição. Rio de Janeiro: Garamond, 2011.

HERSCHMANN, M. Espetacularização e alta visibilidade: a politização do hip-hop no Brasil Contemporâneo. In: FREIRE FILHO, J.; HERSCHMANN, M. (org.).
Comunicação, cultura \& consumo: a (des)construção do espetáculo. Rio de Janeiro: E-Papers, 2005. p. 153-168.

HOLZER, W. A geografia fenomenológica de Eric Dardel. In: DARDEL, E. O homem e a terra: natureza da realidade geográfica. São Paulo: Perspectiva, 2015.

KARNAL, L. O signo aberto. [Entrevista cedida a] Amália Safatle e Magali Cabral. Página 22, São Paulo, 2015.

MARIANO, R. Neopentecostais: sociologia do novo pentecostalismo no Brasil. 4. ed. São Paulo: Loyola, 2012.

ESPETÁCULO. In: Michaelis: moderno dicionário da língua portuguesa. [São Paulo, SP: Melhoramentos, 2015]. Disponível em: https://bit.ly/3xyrdyA. Acesso em: 10 jul. 2017.

MOREIRA, D. D. S. Supermercado da fé: a religião ofertada como bem de consumo através da mídia secular. In: GONGRESSO DE GIÊNGIAS DA COMUNICAÇÃO NA REGIÃO SUDESTE, 16. São Paulo, 2011. Anais [...]. São Paulo: 2011. p. 1-15.

PAEGLE, E. G. M. A "Mcdonaldização" da fé: um estudo sobre os evangélicos brasileiros. Protestantismo em revista, São Leopoldo, v. 17, p. 86-99, 2008.

PEREIRA, C. J. Geografia da religião e a teoria do espaço sagrado: a construção de uma categoria de análise e o desvelar de espacialidades do protestantismo batista. Curitiba: CRV, 2014.

RAMOS, L. C. A práxis homilética e a espetacularização do discurso religioso contemporâneo. Revista Caminhando, São Paulo, v. 11, n. 2, p. 115-127, 2006.

ROSENDAHL, Z. A dimensão do lugar sagrado: ratificando o domínio da emoção e do sentimento do ser-no-mundo. Geo-working papers, Braga, n. 14, p. 5-14, 2008.

SANTANA, L. K. A. Religião e mercado: a mídia empresarial-religiosa. Rever, São Paulo, n. 1, p. 54-67, 2005. 